International Journal of Pure and Applied Mathematics

Volume 112 No. 2 2017, 359-368

ISSN: 1311-8080 (printed version); ISSN: 1314-3395 (on-line version)

url: http://www.ijpam.eu

doi: 10.12732 /ijpam.v112i2.13

\title{
A COMMON FIXED POINT THEOREM FOR A FAMILY OF SELF MAPS IN CONE $b_{2}$-METRIC SPACE
}

\author{
M. Rangamma ${ }^{1}$, P. Rama Bhadra Murthy ${ }^{2}$, P. Mallikarjun Reddy ${ }^{3}$ \\ ${ }^{1,2,3}$ Department of Mathematics \\ Osmania University \\ Telangana, 500007, INDIA
}

\begin{abstract}
An analogue of Banach contraction principle and Kannan's fixed point theorem by defining the minimality in a Banach space was proved by R.George et.al., in Generalized cone b-metric space in [1]. We proved the same fixed point theorem extending it for a family of self-maps in the setting of cone $b_{2}$-metric space by omitting the definition of minimality in a Banach space.
\end{abstract}

AMS Subject Classification: $47 \mathrm{H} 10,54 \mathrm{H} 25$

Key Words: common fixed point, $b_{2}$-metric space, family of self-maps

\section{Introduction}

After the famous Banach contraction principle in 1920, Gahler introduced the concept of 2-metric space with the area of triangle as an underlying example. Many authors proved that there is no relationship between the results in 2metric and in ordinary metric. S.V.R Naidu and Rajendra Prasad showed with examples that a convergent sequence in a 2-metric space need not be a Cauchy sequence and every convergent sequence is a Cauchy sequence if $d$ is continuous (see [3], [17], [16], [15]).

The major generalizations in the field of fixed point theory are Czerwick's bmetric space [13], Huang and Zhang's cone metric space ([8], [14]), Branciari's rectangular metric space [1], etc. These generalizations lead many authors

Received: September 18, 2016

Revised: $\quad$ November 6, 2016

Published: $\quad$ February 1, 2017

$\S_{\text {Correspondence author }}$ (c) 2017 Academic Publications, Ltd.

url: www.acadpubl.eu 
to introduce cone b-metric space $([12],[7])$, cone rectangular metric space [2], generalized cone b-metric space [11], cone 2-metric space [5], $b_{2}$-metric space [10], cone $b_{2}$-metric space. For Quasi-contractions in metric and cone metric spaces, (see [4], [6], [9], [18])

In 2015, Generalized cone b-metric space was introduced by Reny George et.al., by generalizing cone metric space, cone b-metric sapce, and rectangular metric space. They showed that the space need not be Hausdorff and then proved an analogue of Banach contraction principle and a new generalized fixed point theorem which is the union of Kannan contraction and quasi-contraction. They gave the definition of minimality in Banach sapce and used this defining property in proving these theorems.

In this paper, we proved the similar fixed point theorem without assuming the defining property but for a family of self-maps in the setting of cone $b_{2^{-}}$ metric space. We have also given an example to show that cone $b_{2}$-metric spaces is also not necessarily Hausdorff and an example to support our main result.

\section{Preliminaries}

Definition 1. ([8]) Let $E$ be a Banach space and $\theta$ be the zero element of $E$. If $\mathcal{P}$ is a subset of $E$, then $\mathcal{P}$ is called a cone if

1. $\mathcal{P}$ is closed, non-empty and $\mathcal{P} \neq\{\theta\}$.

2. $a, b \in \mathbb{R}, a, b \geq 0, x, y \in \mathcal{P} \Rightarrow a x+b y \in \mathcal{P}$.

3. $x \in \mathcal{P}$ and $-x \in \mathcal{P} \Rightarrow x=\theta$.

Define a partial ordering $\preceq$ in $E$ w.r.t $\mathcal{P}$ by $x \preceq y$ iff $y-x \in \mathcal{P}$. Write $x \prec y$ if $x \preceq y$ and $x \neq y$ where as $x \ll y$ denotes $y-x \in \operatorname{int}(\mathcal{P})$, where $\operatorname{int}(\mathcal{P})$ is interior of $\mathcal{P}$. If $\operatorname{int}(\mathcal{P}) \neq \phi$ then $\mathcal{P}$ is called a solid cone.

The cone $\mathcal{P}$ is called normal if there is a number $k>0$ such that for all $x, y \in E$,

$$
\theta \preceq x \preceq y \Rightarrow\|x\| \leq k\|y\| .
$$

The least positive number $k$ satisfying the above condition is called the normal constant of $\mathcal{P}$. Throughout this paper, we shall assume that $\mathcal{P}$ is a solid cone.

Definition 2. Let $X$ be a non-empty set and $s \geq 1$ be a real number. Let $d: X^{3} \rightarrow E$ be a map satisfying the following conditions:

1. For every pair of distinct points $x, y \in X$, there exist a point $z \in X$ such that $d(x, y, z) \neq \theta$. 
2. If atleast two of the three points $x, y, z$ are equal then $d(x, y, z)=\theta$.

3. $d(x, y, z)=d(p(x, y, z))$ for all $x, y, z \in X$ and for all permutations $p(x, y, z)$.

4. $d(x, y, z) \preceq s[d(x, y, w)+d(x, w, z)+d(w, y, z)]$, for all $x, y, z, w \in X$.

Then $d$ is called cone $b_{2}$-metric and $(X, d)$ is called cone $b_{2}$-metric space.

Example 3. Let $E=\mathbb{R}^{2}, \mathcal{P}=\{(x, y): x, y \geq 0\}$. Define $\|(x, y)\|=\mid$ $x|+| y \mid$ for all $(x, y) \in E$. Let $X=\{(\alpha, 0): \alpha \geq 0\} \cup\{(0,2)\}$. Define the 2-metric $d: X \times X \times X \rightarrow E$ as follows:

$$
d(A, B, C)= \begin{cases}d(p(A, B, C)), & p \text { denotes permutation; } \\ (0,0), & \text { if atleast two of } A, B, C \text { are equal } \\ (\triangle, \triangle), & \text { otherwise, }\end{cases}
$$

where $\triangle=$ square of the area of triangle $A, B, C$. We have,

$$
\begin{aligned}
d((\alpha, 0),(\beta, 0),(0,2)) & \preceq d((\alpha, 0),(\beta, 0),(\gamma, 0)) \\
& +d((\alpha, 0),(\gamma, 0),(0,2))+d((\gamma, 0),(\beta, 0),(0,2))
\end{aligned}
$$

That is, $(\alpha-\beta)^{2} \preceq(\alpha-\gamma)^{2}+(\gamma-\beta)^{2}$, which shows that $d$ is not a cone 2-metric, but a cone $b_{2}$-metric with $s=2$.

Definition 4. ([5]) For any $x \in X$, define the open ball with centre $x$ and radius $r>0$ by

$$
B(x, r)=\{y \in X:\|d(x, y, a)\|<r \text { for all } a \in X\}
$$

Let $\tau$ be the collection of all subsets $A$ of $X$ satisfying that for each $x \in A$, there exists $r>0$ such that $B(x, r) \subseteq A$. Then $\tau$ defines a topology for the cone $b_{2}$-metric space $(X, d)$ but is not necessarily Hausdorff space. For instance, consider the above example.

The ball with centre $(0,0)$ and radius 2 is

$$
B((0,0), 2)=\{(0,0),(0,2),(\alpha, 0): 0<\alpha<1\} .
$$

The ball with centre $(0,2)$ and radius 2 is

$$
B((0,2), 2)=\{(0,0),(0,2)\}
$$

It is clear that we cannot choose $r_{1}, r_{2}>0$ such that $B((0,0), 2) \cap B((0,2), 2)=$ $\phi$ and hence $(X, d)$ is not Hausdorff. 
Definition 5. ([10]) Let $\left\{x_{n}\right\}$ be a sequence in cone $b_{2}$-metric space $(X, d)$.

1. $\left\{x_{n}\right\}$ is said to be $b_{2}$-convergent to $x \in X$ if $\lim _{n \rightarrow \infty} d\left(x_{n}, x, a\right)=\theta$, for all $a \in X$.

2. $\left\{x_{n}\right\}$ is said to be a $b_{2}$-Cauchy in $X$ if $\lim _{m, n \rightarrow \infty} d\left(x_{n}, x_{m}, a\right)=\theta$, for all $a \in X$.

3. $(X, d)$ is said to be $b_{2}$-complete if every $b_{2}$-Cauchy sequence is a $b_{2^{-}}$ convergent in $X$.

\section{Main Results}

Lemma 6. Let $(X, d)$ be a $b_{2}$-complete cone $b_{2}$-metric space with coefficient $s \geq 1$ and $\mathcal{P}$ be an underlying cone. If $\left\{x_{n}\right\}$ is any sequence in $X$, then we have

$$
d\left(x_{n+1}, x_{n}, a\right) \preceq \beta d\left(x_{n}, x_{n-1}, a\right) \Rightarrow d\left(x_{n+1}, x_{n}, x_{t}\right)=\theta,
$$

for all $a \in X$ and $m \in \mathbb{N} \cup\{0\}$ where $\beta \in\left[0, \frac{1}{s}\right)$.

Proof. Since $d\left(x_{n+1}, x_{n}, a\right) \preceq \beta d\left(x_{n}, x_{n-1}, a\right)$. By the repeated application of this to $d\left(x_{n+1}, x_{n}, a\right)$ gives,

$$
d\left(x_{n+1}, x_{n}, a\right) \preceq \beta^{n} d\left(x_{1}, x_{o}, a\right) .
$$

If $m<n$, then

$$
\begin{aligned}
d\left(x_{n+1}, x_{n}, x_{m}\right) & \preceq k d\left(x_{n}, x_{n-1}, x_{m}\right) \\
& \preceq \beta d\left(x_{n-1}, x_{n-2}, x_{m}\right) \\
& \vdots \\
& \preceq \beta^{n-m} d\left(x_{m+1}, x_{m}, x_{m}\right) \\
& =\theta .
\end{aligned}
$$

Therefore,

$$
d\left(x_{n+1}, x_{n}, x_{m}\right)=\theta
$$

for all $m$ with $m<n$.

If $m>n$ and by using (3) then we get,

$$
d\left(x_{n+1}, x_{n}, x_{m}\right) \preceq s\left[d\left(x_{n+1}, x_{n}, x_{m-1}\right)+d\left(x_{n+1}, x_{m-1}, x_{m}\right)\right.
$$




$$
\begin{aligned}
& \left.+d\left(x_{m-1}, x_{n}, x_{m}\right)\right] \\
& =s d\left(x_{n+1}, x_{n}, x_{m-1}\right) \\
& \preceq s^{2}\left[d\left(x_{n+1}, x_{n}, x_{m-2}\right)+d\left(x_{n+1}, x_{m-2}, x_{m-1}\right)\right. \\
& \left.+d\left(x_{m-2}, x_{n}, x_{m-1}\right)\right] \\
& =s^{2} d\left(x_{n+1}, x_{n}, x_{m-2}\right) \\
& \preceq s^{3} d\left(x_{n+1}, x_{n}, x_{m-3}\right) \\
& \vdots \\
& \preceq s^{m-n} d\left(x_{n+1}, x_{n}, x_{n}\right) \\
& =\theta .
\end{aligned}
$$

Therefore,

$$
d\left(x_{n+1}, x_{n}, x_{m}\right)=\theta
$$

for all $m$ with $m>n$.

Since the case is obvious with $m=n$, from (3) and (4) we have,

$$
d\left(x_{n+1}, x_{n}, x_{m}\right)=\theta
$$

for all $m \in \mathbb{N} \cup\{0\}$.

Theorem 7. Let $(X, d)$ be a $b_{2}$-complete cone $b_{2}$-metric space with coefficient $s \geq 1$ and $\mathcal{P}$ be the underlying cone. Let $\left\{T_{i}\right\}_{i=1}^{\infty}$ be family of self-maps on $X$ satisfying

$$
d\left(T_{i} x, T_{j} y, a\right) \preceq \lambda\left[d\left(x, T_{i} x, a\right)+d\left(y, T_{j} y, a\right)\right]+L u(x, y, a),
$$

for all $i, j=1,2,3 \ldots$ and $x, y, a \in X$ with $L \geq 0$ and

$$
(\lambda+L s)(s+1)<1
$$

where $u(x, y, a) \in\left\{d\left(x, T_{i} x, a\right)+d\left(y, T_{j} y, a\right), d\left(x, T_{i} x, a\right), d\left(y, T_{j} y, a\right)\right\}$. Then $\left\{T_{i}\right\}$ has a unique common fixed point in $X$.

Proof. Let $x_{0} \in X$ be arbitrary. Define the sequence $\left\{x_{n}\right\}$ by $x_{n}=T_{n}\left(x_{n-1}\right)$, $n \in \mathbb{N}$.

$$
\begin{aligned}
d\left(x_{n}, x_{n+1} a\right) & =d\left(T_{n}\left(x_{n-1}\right), T_{n+1} x_{n}, a\right) \\
& \preceq \lambda\left[d\left(x_{n-1} x_{n}, a\right)+d\left(x_{n}, x_{n+1}, a\right)\right]+L u\left(x_{n-1}, x_{n}, a\right)
\end{aligned}
$$

where, $u\left(x_{n-1}, x_{n}, a\right) \in\left\{d\left(x_{n-1} x_{n}, a\right)+d\left(x_{n}, x_{n+1}, a\right), d\left(x_{n-1}, x_{n+1}, a\right)\right.$, $\left.d\left(x_{n}, x_{n}, a\right)\right\}$. Now we consider the three cases of $u$. 
Case(i): If $u\left(x_{n-1}, x_{n}, a\right)=d\left(x_{n-1} x_{n}, a\right)+d\left(x_{n}, x_{n+1}, a\right)$, then we get, $[1-$ $(\lambda+L)] d\left(x_{n}, x_{n+1}, a\right) \preceq(\lambda+L) d\left(x_{n-1} x_{n}, a\right)$ for all $a \in X$.

That is,

$$
d\left(x_{n}, x_{n+1}, a\right) \preceq \beta_{1} d\left(x_{n-1} x_{n}, a\right),
$$

where, $\beta_{1}=\frac{\lambda+L}{1-(\lambda+L)}$.

Case(ii): If $u\left(x_{n-1}, x_{n}, a\right)=d\left(x_{n-1}, x_{n+1}, a\right)$, then we get,

$$
d\left(x_{n}, x_{n+1} a\right) \preceq \lambda\left[d\left(x_{n-1} x_{n}, a\right)+d\left(x_{n}, x_{n+1}, a\right)\right]+L d\left(x_{n-1}, x_{n+1}, a\right)
$$

for all $a \in X$. In particular, taking $a=x_{n-1}$, we get

$d\left(x_{n}, x_{x+1}, x_{n-1}\right) \preceq \lambda d\left(x_{n}, x_{x+1}, x_{n-1}\right)$ and since $\lambda<1$, we have

$$
d\left(x_{n}, x_{x+1}, x_{n-1}\right)=\theta .
$$

From (8), using triangle inequality and (5), we get,

$$
\begin{aligned}
d\left(x_{n}, x_{n+1} a\right) & \preceq \lambda\left[d\left(x_{n-1} x_{n}, a\right)+d\left(x_{n}, x_{n+1}, a\right)\right] \\
& +\operatorname{Ls}\left[d\left(x_{n-1}, x_{n+1}, x_{n}\right)+d\left(x_{n-1}, x_{n}, a\right)+d\left(x_{n}, x_{n+1}, a\right)\right],
\end{aligned}
$$

which implies that,

$$
\begin{aligned}
{[1-(\lambda+L s)] d\left(x_{n}, x_{n+1} a\right) } & \preceq(\lambda+L s) d\left(x_{n-1} x_{n}, a\right) \\
\text { i.e., } d\left(x_{n}, x_{n+1}, a\right) & \preceq \beta_{2} d\left(x_{n-1} x_{n}, a\right),
\end{aligned}
$$

where, $\beta_{2}=\frac{\lambda+L s}{1-(\lambda+L s)}$.

Case(iii): If $u\left(x_{n-1}, x_{n}, a\right)=d\left(x_{n}, x_{n}, a\right)$, then we get

$$
\begin{aligned}
(1-\lambda) d\left(x_{n}, x_{n+1}, a\right) & \preceq \lambda d\left(x_{n-1} x_{n}, a\right) \\
\text { i.e., } d\left(x_{n}, x_{n+1}, a\right) & \preceq \beta_{3} d\left(x_{n-1} x_{n}, a\right),
\end{aligned}
$$

where $\beta_{3}=\frac{\lambda}{1-\lambda}$.

Write $\beta=\max \left\{\beta_{1}, \beta_{2}, \beta_{3}\right\}$.

Since $\lambda<\lambda+L<\lambda+L s<\frac{1}{s+1}<\frac{1}{s}$, we have $\beta<\frac{1}{s}$.

Now (7),(10) and (11) can be written as

$$
d\left(x_{n}, x_{n+1}, a\right) \preceq \beta d\left(x_{n-1} x_{n}, a\right),
$$

where, $\beta<\frac{1}{s}$.

The repeated application of (12) gives,

$$
d\left(x_{n}, x_{n+1}, a\right) \preceq \beta^{n} d\left(x_{n-1} x_{n}, a\right),
$$


where, $\beta<\frac{1}{s}$.

Using Lemma (1), we have

$$
d\left(x_{n+1}, x_{n}, x_{m}\right)=\theta
$$

for all, $m, n=0,1,2, \ldots$

Let $m>n$. Using triangle inequality and (14) we get,

$$
\begin{aligned}
d\left(x_{n}, x_{m}, a\right) & \preceq s\left[d\left(x_{n}, x_{m}, x_{n+1}\right)+d\left(x_{n}, x_{n+1}, a\right)+d\left(x_{n+1}, x_{m}, a\right)\right] \\
& =s \beta^{n} d\left(x_{1}, x_{0}, a\right)+s d\left(x_{n+1}, x_{m}, a\right) \\
& \preceq s \beta^{n} d\left(x_{1}, x_{0}, a\right)+s^{2}\left[d\left(x_{n+1}, x_{m}, x_{n+2}\right)\right. \\
& \left.+d\left(x_{n+1}, x_{n+2}, a\right)+d\left(x_{n+2}, x_{m}, a\right)\right] \\
& \preceq s \beta^{n} d\left(x_{1}, x_{0}, a\right)+s^{2} \beta^{n+1} d\left(x_{1}, x_{0}, a\right) \\
& +s^{2} d\left(x_{n+2}, x_{m}, a\right)
\end{aligned}
$$

Continuing this process, we get

$$
\begin{aligned}
d\left(x_{n}, x_{m}, a\right) & \preceq\left(s \beta^{n}+s^{2} \beta^{n+1}+s^{3} \beta^{n+2}+\ldots+s^{m-n-2} \beta^{m-3}\right. \\
& \left.+s^{m-n-1} \beta^{m-2}\right) d\left(x_{1}, x_{0}, a\right)+s^{m-n-1} \beta^{m-1} d\left(x_{1}, x_{0}, a\right) \\
& =s \beta^{n}\left[1+s \beta+s^{2} \beta^{2}+\ldots+s^{m-n-1} \beta^{m-n-1}\right] d\left(x_{1}, x_{0}, a\right) \\
& \preceq s \beta^{n} \sum_{i=1}^{\infty}(s \beta)^{n} d\left(x_{1}, x_{0}, a\right) \\
& \preceq \frac{s \beta^{n}}{1-s \beta} d\left(x_{1}, x_{0}, a\right) .
\end{aligned}
$$

Thus we have

$$
d\left(x_{n}, x_{m}, a\right) \preceq \frac{s \beta^{n}}{1-s \beta} d\left(x_{1}, x_{0}, a\right),
$$

where $\beta<\frac{1}{s}$.

Let $\theta \ll c$ be given. Choose $\delta>0$ such that $c+N_{\delta}(\theta) \subseteq \mathcal{P}$ where $N_{\delta}(\theta)=\{y \in$ $E:\|y\|<\delta\}$. Also choose a natural number $n_{1}$ such that $\frac{s \beta^{n}}{1-s \beta} d\left(x_{1}, x_{0}, a\right) \in$ $N_{\delta}(\theta)$ for all $n \geq n_{1}$.

Thus we have $d\left(x_{n}, x_{m}, a\right) \ll c$ for all $n \geq n_{1}$ which shows that $\left\{x_{n}\right\}$ is a Cauchy sequence in $X$. By the completeness of $(X, d)$, there is an element $x \in X$ such that $x_{n} \rightarrow x$ as $n \rightarrow \infty$.

Now we show that this $x$ is the common fixed point of the family of self-maps $\left\{T_{i}\right\}$.

Let $n \in \mathbb{N}$ be arbitrary.

$$
d\left(T_{n} x, x, a\right) \preceq s\left[d\left(T_{n} x, x, x_{n}\right)+d\left(T_{n} x, x_{n}, a\right)+d\left(x_{n}, x, a\right)\right]
$$




$$
\begin{aligned}
& =s\left[d\left(T_{n} x, x, x_{n}\right)+d\left(x_{n}, x, a\right)\right]+s d\left(T_{n} x, T_{n} x n-1, a\right) \\
& \preceq s\left[d\left(T_{n} x, x, x_{n}\right)+d\left(x_{n}, x, a\right)\right] \\
& +s \lambda\left[d\left(x, T_{n} x, a\right)+d\left(x_{n-1}, x_{n}, a\right)\right]+\operatorname{Lsu}\left(x, x_{n-1}, a\right),
\end{aligned}
$$

where $u\left(x, x_{n-1}, a\right) \in\left\{d\left(x, T_{n} x, a\right)+d\left(x_{n-1}, x_{n}, a\right)\right.$, $\left.d\left(x, x_{n}, a\right), d\left(x_{n-1}, T_{n} x, a\right)\right\}$.

Here also we consider the three cases of $u$.

Case(i): If $u\left(x, x_{n-1}, a\right)=d\left(x, T_{n} x, a\right)+d\left(x_{n-1}, x_{n}, a\right)$, we have

$$
\begin{aligned}
d\left(T_{n} x, x, a\right) & \preceq s\left[d\left(T_{n} x, x, x_{n}\right)+d\left(x_{n}, x, a\right)\right] \\
& +s(\lambda+L)\left[d\left(x, T_{n} x, a\right)+d\left(x_{n-1}, x_{n}, a\right)\right]
\end{aligned}
$$

Letting $n \rightarrow \infty$ gives $d\left(T_{n} x, x, a\right) \preceq s(\lambda+L) d\left(T_{n} x, x, a\right)$.

Since $s(\lambda+L)<1$ we have $d\left(T_{n} x, x, a\right)=\theta$ for all $a \in X$. Which implies $T_{n} x=x$. Since $n$ is arbitrary, we have $T_{i} x=x, i=1,2,3, \ldots$ in this case.

Case(ii): If $u\left(x, x_{n-1}, a\right)=d\left(x, x_{n}, a\right)$, we have

$$
\begin{aligned}
d\left(T_{n} x, x, a\right) & \preceq s\left[d\left(T_{n} x, x, x_{n}\right)+d\left(x_{n}, x, a\right)\right] \\
& +s \lambda\left[d\left(x, T_{n} x, a\right)+d\left(x_{n_{1}}, x_{n}, a\right)\right]+\operatorname{Lsd}\left(x, x_{n}, a\right)
\end{aligned}
$$

Letting $n \rightarrow \infty$ gives $d\left(T_{n} x, x, a\right) \preceq s \lambda d\left(T_{n} x, x, a\right)$.

Since $s \lambda<1$ we have $d\left(T_{n} x, x, a\right)=\theta$, for all $a \in X$. Which implies $T_{n} x=x$. Since $n$ is arbitrary, we have $T_{i} x=x, i=1,2,3, \ldots$ in this case.

Case(iii): If $u\left(x, x_{n-1}, a\right)=d\left(x_{n-1}, T_{n} x, a\right)$, we have

$$
\begin{aligned}
d\left(T_{n} x, x, a\right) & \preceq s\left[d\left(T_{n} x, x, x_{n}\right)+d\left(x_{n}, x, a\right)\right] \\
& +s \lambda\left[d\left(x, T_{n} x, a\right)+d\left(x_{n_{1}}, x_{n}, a\right)\right]+\operatorname{Lsd}\left(x_{n-1}, T_{n} x, a\right) \\
& \preceq s\left[d\left(T_{n} x, x, x_{n}\right)+d\left(x_{n}, x, a\right)\right] \\
& +s \lambda\left[d\left(x, T_{n} x, a\right)+d\left(x_{n_{1}}, x_{n}, a\right)\right] \\
& +L s^{2}\left[d\left(x_{n-1}, T_{n} x, x\right)+d\left(x_{n-1}, x, a\right)+d\left(x, T_{n} x, a\right)\right]
\end{aligned}
$$

Letting $n \rightarrow \infty$ gives $d\left(T_{n} x, x, a\right) \preceq s(\lambda+L s) d\left(T_{n} x, x, a\right)$.

Since $s(\lambda+L s)<1$ we have $d\left(T_{n} x, x, a\right)=\theta$ for all $a \in X$. Which implies $T_{n} x=x$. Since $n$ is arbitrary, we have $T_{i} x=x, i=1,2,3, \ldots$ in this case also. Hence $x$ is the common fixed point of the family of self maps $\left\{T_{i}\right\}, i \in \mathbb{N}$. The uniqueness can be proved easily.

Example 8. Consider the example 3 which is cone $b_{2}$-metric space with $s=2$. Define $T_{i}: X \rightarrow X$ as follows: 
$T_{i}(\alpha, 0)=\left(\frac{\alpha}{i+4}, 0\right)$ and $T_{i}(0,2)=(0,0)$ for all $(\alpha, 0) \in X, i \in \mathbb{N}$.

Choose $\lambda=\frac{1}{4}, L=\frac{1}{25}$. Clearly $(\lambda+L s)(s+1)<1$.

Considering the contractive condition with $\lambda=\frac{1}{4}, L=\frac{1}{25}$,

$d\left(T_{i}(A), T_{j}(B), C\right) \preceq\left[d\left(A, T_{i}(A), C\right)+d\left(B, T_{j}(B), C\right)\right]+\frac{1}{25} u(A, B, C)$ we have the following six cases.

(i) $A \in X, B \in X, C \in X$;

(ii) $A \in Y, B \in Y, C \in X$;

(iii) $A \in X, B \in Y, C \in X$;

(iv) $A \in Y, B \in Y, C \in Y$;

(v) $A \in X, B \in X, C \in Y$;

(vi) $A \in X, B \in Y, C \in Y$.

All the cases are trivial, except (v) and (vi) in which case we have

$$
\begin{aligned}
d\left(T_{i}(\alpha, 0), T_{j}(\beta, 0),(0,2)\right) & \preceq \frac{1}{4}\left[d\left((\alpha, 0),\left(\frac{\alpha}{i+4}, 0\right),(0,2)\right)\right. \\
& \left.+d\left((\beta, 0),\left(\frac{\beta}{i+4}, 0\right),(0,2)\right)\right] \\
& +\frac{1}{25} u((\alpha, 0),(\beta, 0),(0,2))
\end{aligned}
$$

Since,

$\left(\frac{\alpha}{i+4}-\frac{\beta}{i+4}\right)^{2} \preceq \frac{1}{4}\left[\left(\frac{i+3}{i+4} \alpha\right)^{2}+\left(\frac{j+3}{j+4} \beta\right)^{2}\right]+\frac{1}{25} u((\alpha, 0),(\beta, 0),(0,2))$ is always true for all $i, j \in \mathbb{N}$ and $\alpha, \beta \geq 0$, case (v) is also satisfied. Case (vi) is also true with similar reason. Hence, the family of self-maps $\left\{T_{i}\right\}_{i=1}^{\infty}$ satisfy the contractive condition of the main theorem. Thus, $\left\{T_{i}\right\}_{i=1}^{\infty}$ share a common fixed point which is $(0,0)$.

\section{Acknowledgments}

The research was supported by Council of Scientific and Industrial Research (CSIR), New Delhi, India. 


\section{References}

[1] A.branciari, A fixed point theorem of Banach-Caccippoli type on a class of generalised metric spaces, Publ. Math. Debrecen, 57 (2000), 31-37.

[2] A.Azam, M.Arshad, I.Beg, Banach contraction principle on cone rectangular metric spaces, Applicable Anal. Discrete Math, 3 (2009), 236-241.

[3] Ashok K. Sharma, A note on fixed points in 2-metric spaces, Indian J. pure appl. Math., 11, No.12 (1980), 1580-1583.

[4] Brian Fisher, Quasi-contractions on metric spaces, Proc. Amer. Math. Soc., 75, No. 2 (1979), 321-325.

[5] B.Singh et al, Cone 2-metric space and fixed point theorem of contractive mappings, Commentationes Mathematicae, 52, No.2 (2012), 143-151.

[6] Dejan Ilić, Vladimir Rakocević, Quasi-Contraction on a cone metric space, Appl. Math. Letters., 22 (2009), 728-731.

[7] Huang and $\mathrm{Xu}$, Fixed point theorems of contractive mappings in cone $b$-metric spaces and applications, Fixed Point Theory and Applications, 2013, 2013:112.

[8] Huang and Zhang, Cone metric spaces and fixed point theorems of contractive mappings, J. Math. Anal. Appl., 332 (2007), 1468-1476.

[9] Ljiljana Gajić and Vladimir Rakocević, Quasi-Contractions on a non-normal cone metric space, Func. Anal. and its Appl., 46, No.1(2012), 62-65.

[10] Mustafa et.al, $b_{2}$-metric spaces and some fixed point theorems, Fixed Point Theory and Applications, 2014, 2014:144.

[11] Reny George et.al., Generalized cone b-metric spaces and contraction principles, Matematicki vesnik, 67, No. 4 (2015), 246-257.

[12] N. Hussain, M.H. Shah, KKM mappings in cone b-metric spaces, Computers and Mathematics with Applications, 62 (2011), 1677-1684.

[13] S. Czerwik, Contraction mappings in b-metric spaces. Acta Math. Inform. Univ. Ostrav, 1 (1993), 5-11.

[14] Sh.Rezapour, R.Hamlbarani, Some notes on the paper "Cone metric spaces and fixed point theorems of contractive mappings", J. Math. Anal. Appl., 345 (2008), 719-724.

[15] S.N.Lal and A.K.Singh, An analogue of Banach's contraction principle for 2-metric spaces, Bull. Austral. Math. Soc., 17, No.8 (1986), 974-993.

[16] S.V.R. Naidu and J. Rajendra Prasad, Fixed point theorems in 2-metric spaces, Indian J. pure appl. Math., 17, No.8 (1986), 974-993.

[17] V.S. Gahler , 2-metrische Raume und ihre topologisehe Struktur, Math. Nachr., 26 (1962), 115-118.

[18] Z. Kadelburg et al, Remarks on "Quasi-Contraction on a cone metric space", Appl. Math. Letters., 22 (2009), 1674-1679. 